\title{
Imprescindible, insuficiente, incoherente e instrumental: formación docente para aprender a convivir
}

\section{Essential, insufficient, incoherent, and instrumental: Teacher training to learn to live together}

\author{
CÉCIle BARBeito Thonon*
}

Este artículo analiza cinco estudios de casos europeos (Croacia, España, Francia, Italia y Suecia) para comparar las políticas de formación de profesorado relativas a la transformación de conflictos y la convivencia escolar. Examina leyes educativas, currículos y políticas de formación de profesorado de cada país y verifica en la práctica si se garantiza la formación inicial y continuada en contenidos relacionados con la transformación de conflictos y hasta qué punto la administración hace un seguimiento suficiente de la efectividad de las políticas de convivencia. A pesar de identificar algunas buenas prácticas, se concluye que las políticas de formación de profesorado en materia de convivencia en los países estudiados son imprescindibles, pero insuficientes, incoherentes e instrumentales, aún lejos del objetivo de formar a personas a aprender a vivir juntos.

This article analyses five European case studies (Croatia, France, Italy, Spain, and Sweden), comparing teacher training policies on conflict transformation and peaceful coexistence at school. After analysing educational laws, curriculums and teacher training policies in each of those countries, the article further verifies to what extent pre-service and in-service teacher training relating to conflict transformation is actually guaranteed in practice, and to what extent the administration sufficiently monitors the effectiveness of their peaceful coexistence policies. Despite identifying some good practices, the article concludes that teacher training policies on coexistence in those examined countries are essential but still insufficient, incoherent, and instrumental, and far from achieving the objective of training pupils to learn to live together.

\section{Palabras clave:}

convivencia, conflicto, formación docente, políticas educativas

\section{Keywords:}

coexistence, conflicte, teacher training, educational policies

Recibido: 20 de enero de 2021 | Aceptado para su publicación: 2 de septiembre de 2021| Publicado: 23 de noviembre de 2021

Cómo citar: Barbeito Thonon, C. (2021). Imprescindible, insuficiente, incoherente e instrumental: formación docente para aprender a convivir. Sinéctica, Revista Electrónica de Educación, (57), e1285. https://doi.org/10.31391/S2007-7033(2021)0057-018

\footnotetext{
* Máster en Evaluación Educativa. Formadora e investigadora en la Escuela de Cultura de Pau de la Universidad Autónoma de Barcelona. Líneas de investigación: ciencias políticas, cultura de paz y salud mental en casos de violencia política. Correo electrónico: cecile.barbeito@uab.es/https://orcid.org/0000-0003-4653-588X
} 


\section{INTRODUCCIÓN}

$\mathrm{N}$

i los centros escolares ni las aulas son ecosistemas aislados; a menudo están afectados por las problemáticas sociales de su entorno, como la segregación escolar, la polarización ideológica respecto de algunos conflictos sociales, la estigmatización de ciertos colectivos, especialmente pertenecientes a minorías, acrecentados por medios de comunicación partidistas, burbujas informativas y fake news. Estas demandan al alumnado actual competencias asociadas al aprendizaje del abordaje de los conflictos.

Estos retos sociales parecen demandar que la enseñanza promueva el aprendizaje de competencias que favorezcan el aprender a vivir juntos desde el aprecio del Otro y el abordaje de los conflictos (Delors, 1996). ¿Hasta qué punto se puede decir que los centros escolares contribuyen al aprendizaje de competencias útiles para los retos actuales de la sociedad? ¿Hasta qué punto se favorecen las condiciones para que el profesorado pueda formar en estos contenidos? En este artículo analizamos cómo, desde la formación docente del profesorado de Croacia, España, Francia, Italia y Suecia, se posibilita el aprendizaje de competencias que favorezcan la convivencia.

\section{JUSTIFICACIÓN: VIOLENCIA -Y CONVIVENCIA- EN LAS ESCUELAS}

Diagnosticar la situación de violencia o de convivencia en los centros escolares es siempre un reto, ya que los análisis suelen focalizarse mucho más en el primer fenómeno -la violencia- que en el segundo -la convivencia-, y más en la violencia directa (física, psicológica) que en otras formas más intangibles (actitudes discriminatorias excluyentes, xenófobas) presentes en algunos estudios comparativos internacionales (Richardson \& Fen, 2016). A menudo, es posible identificar, de manera simultánea, situaciones de violencia y de convivencia en los centros. Sin embargo, describir la convivencia escolar con datos comparativos es todavía un reto no alcanzado por las estadísticas existentes en el ámbito internacional (Barbeito et al., 2018).

Aun así, y reconociendo que representa una visión parcial e incompleta de la realidad escolar, para este estudio sigue siendo válido analizar la situación de violencia en las escuelas, al ser el argumento más contundente para justificar la importancia de reforzar las políticas de convivencia. Aunque sea compatible hallar violencia y convivencia a la vez en un mismo centro, la tolerancia cero a la violencia que debería imperar en este justifica seguir partiendo de la violencia escolar.

La violencia en las escuelas puede tomar múltiples formas e intensidades en función del contexto: los estudios comparativos muestran grandes variaciones de acuerdo con los países. Según el Fondo de las Naciones Unidas para la Infancia (Unicef, 2018), las principales tipologías de violencia en las escuelas responden al acoso escolar, el ciberacoso, las peleas y otras agresiones físicas, el castigo físico, los ataques a las escuelas o al profesorado, y la violencia sexual. Esta tipificación, de nuevo, se circunscribe únicamente a la violencia directa y deja de lado, por tanto, grandes categorías de violencia en las escuelas relacionadas con la violencia estructural y la violencia cultural (Galtung, 1990). 
En relación con el acoso escolar, más de un 10\% del alumnado de 11 a 15 años lo padece (Inchley et al., 2020b) (ver gráfica 1), aunque cabe destacar que la variación es grande en función de los países y las regiones (Inchley et al., 2020a).

Gráfica 1. Jóvenes de 13 años que han padecido acoso escolar y ciberacoso al menos dos veces durante los últimos dos meses (2018) (\%)

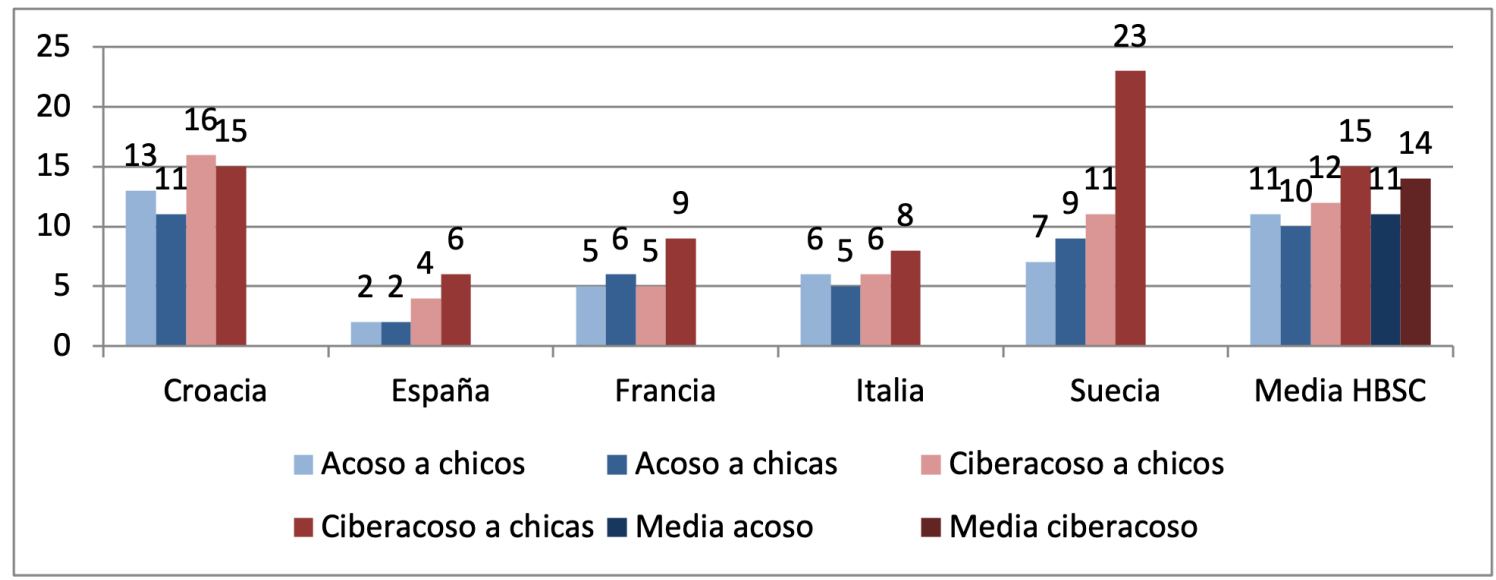

Fuente: Inchley et al., 2020b, pp. 98 y 102.

Estos datos no solo varían considerablemente en cada país, sino también en función de algunas variables individuales: en cuanto a la de género, no observamos diferencias significativas en el padecimiento de acoso escolar, pero sí en el ciberacoso (las chicas son más proclives a padecerlo) (ver gráfica 1) (Inchley et al., 2020a). Los chicos tienen más tendencia a sufrir violencia y amenazas físicas (ver gráfica 2). Las chicas, en cambio, suelen tener más probabilidades de padecer acoso psicológico (marginación, rumores) (Unicef, 2018).

Gráfica 2. Jóvenes de 13 años que han participado en una pelea al menos tres veces durante los últimos doce meses (2018) (\%)

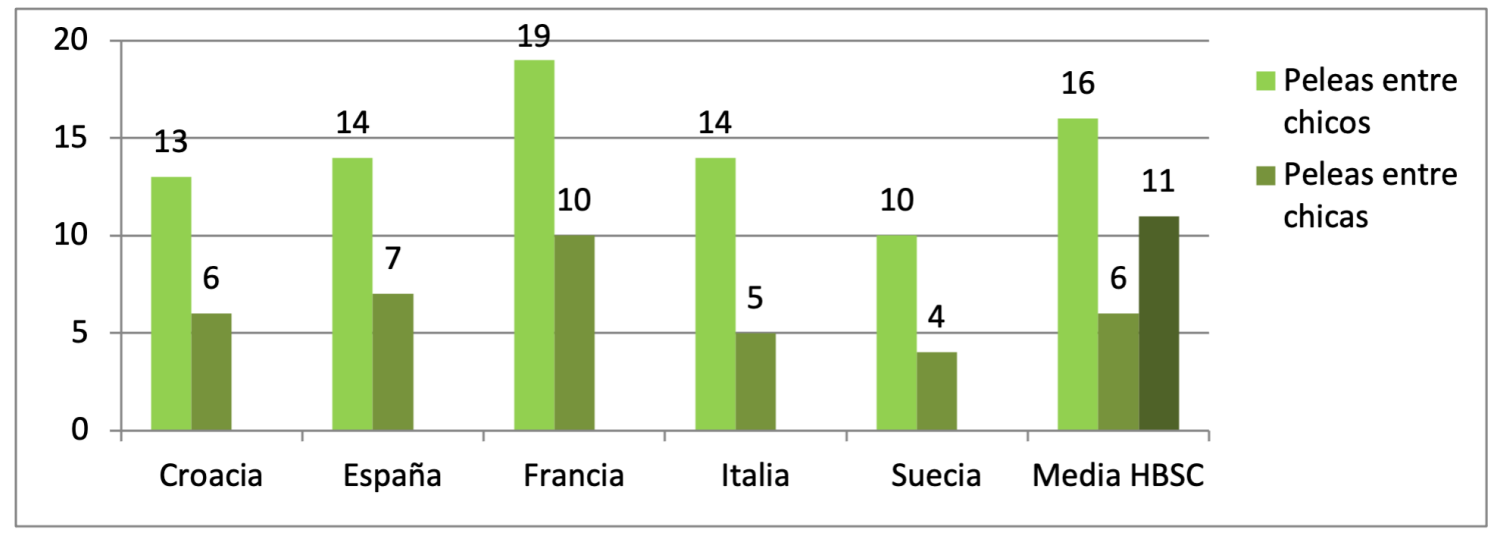

Fuente: Inchley et al., 2020b, p. 105.

En relación con la edad, observamos que, a mayor edad del alumnado, aumenta la perpetración de acoso, mientras que, a menor edad, se incrementa la proporción de victimización, como puede parecer lógico en una dinámica en la que el poder sobre 
la otra persona juega un papel relevante. La edad media de perpetración de acoso y ciberacoso en los chicos es de 15 años, mientras que la de las chicas, de 13 años (Inchley et al., 2020a, p. 30).

En cuanto a la variable socioeconómica, esta no parece determinar diferencias significativas en la perpetración o victimización de violencia en las escuelas (Inchley et al., 2020a).

La comparación entre países en las gráficas 1 y 2 permite observar algunos patrones comunes, como la prevalencia de las peleas entre chicos (entre seis y nueve puntos más que en las peleas entre chicas) o la prevalencia del ciberacoso entre chicas, con patrones algo distintos entre los países analizados.

La mayoría de estudios cuantitativos (Inchley et al., 2020a; Richardson \& Fen, 2016) se centran en caracterizar los perfiles del alumnado perpetrador y víctima de la violencia escolar (factores individuales); sin embargo, hay que tener en cuenta que en la convivencia y la violencia escolar también entran en juego otros actores, como el profesorado. Siguiendo la tipología del Unicef, el profesorado tendría parte de responsabilidad en los castigos corporales (prohibido en 58 países del mundo -incluyendo cuatro de los países estudiados, a excepción de Italia-), lo que supone la protección legal del 12\% de niños, niñas y adolescentes del mundo (Global Initiative to End All Corporal Punishment of Children, 2020) $y$ en el acoso sexual de diferentes niveles de gravedad.

Analizar el impacto de la violencia y el clima de convivencia en las escuelas permite valorar el bienestar infantil, su desarrollo social y su salud -presente y futura-, que repercuten en las actitudes y el aprendizaje (Richardson \& Fen, 2016), e influyen de manera importante en la tarea educativa. La capacidad del profesorado para afrontar este reto se aborda en el siguiente apartado.

\section{FORMACIÓN INSUFICIENTE DEL PROFESORADO}

Aunado a la realidad de violencia descrita, no menospreciable, en los centros se observa que, a menudo, el profesorado no tiene la formación suficiente para afrontar los conflictos en el aula. En Croacia, un estudio evaluativo revela que un porcentaje altísimo de docentes encuestados (entre el 65\% y el 85\%) afirma no haber reaccionado ante casos de acoso escolar, sea porque no lo identificaron como acoso o porque no se sintieron responsables o competentes para enfrentar el problema (Pregrad, 2015). Datos similares se han registrado en España, donde el 76\% del profesorado reconoce no sentirse suficientemente preparado para afrontar las situaciones de acoso escolar (Sidrera et al., 2019).

La formación del profesorado para atender conflictos en el centro es necesaria para gestionar los conflictos y prevenir la violencia, además de la correcta aplicación de los protocolos obligatorios sobre violencia escolar en varias regiones de España (en Croacia y Francia, sobre acoso escolar y acoso escolar homófobo), aunque en pocas ocasiones la aplicación de estos protocolos vaya asociada a una formación suficiente.

Más allá de las necesidades operativas mencionadas, y como argumentaremos a lo largo de este artículo, el profesorado no dispone de las condiciones suficientes para enseñar al alumnado las competencias básicas de transformación de conflictos. 


\section{DE LA VIOLENCIA A LA CONVIVENCIA ESCOLAR: EL PAPEL DEL PROFESORADO ¿IMPRESCINDIBLE?}

Una vez analizado el panorama actual de violencia en las escuelas de los países europeos estudiados y constatada la formación insuficiente del profesorado, es pertinente cuestionar si, efectivamente, formar al profesorado en transformación de conflictos y promoción de la convivencia es la estrategia más efectiva para conseguir una mejora de la convivencia. Como identifican Maternowska, Potts y Fry (2016), en la violencia que afecta la infancia y la juventud entran en juego una multitud de factores.

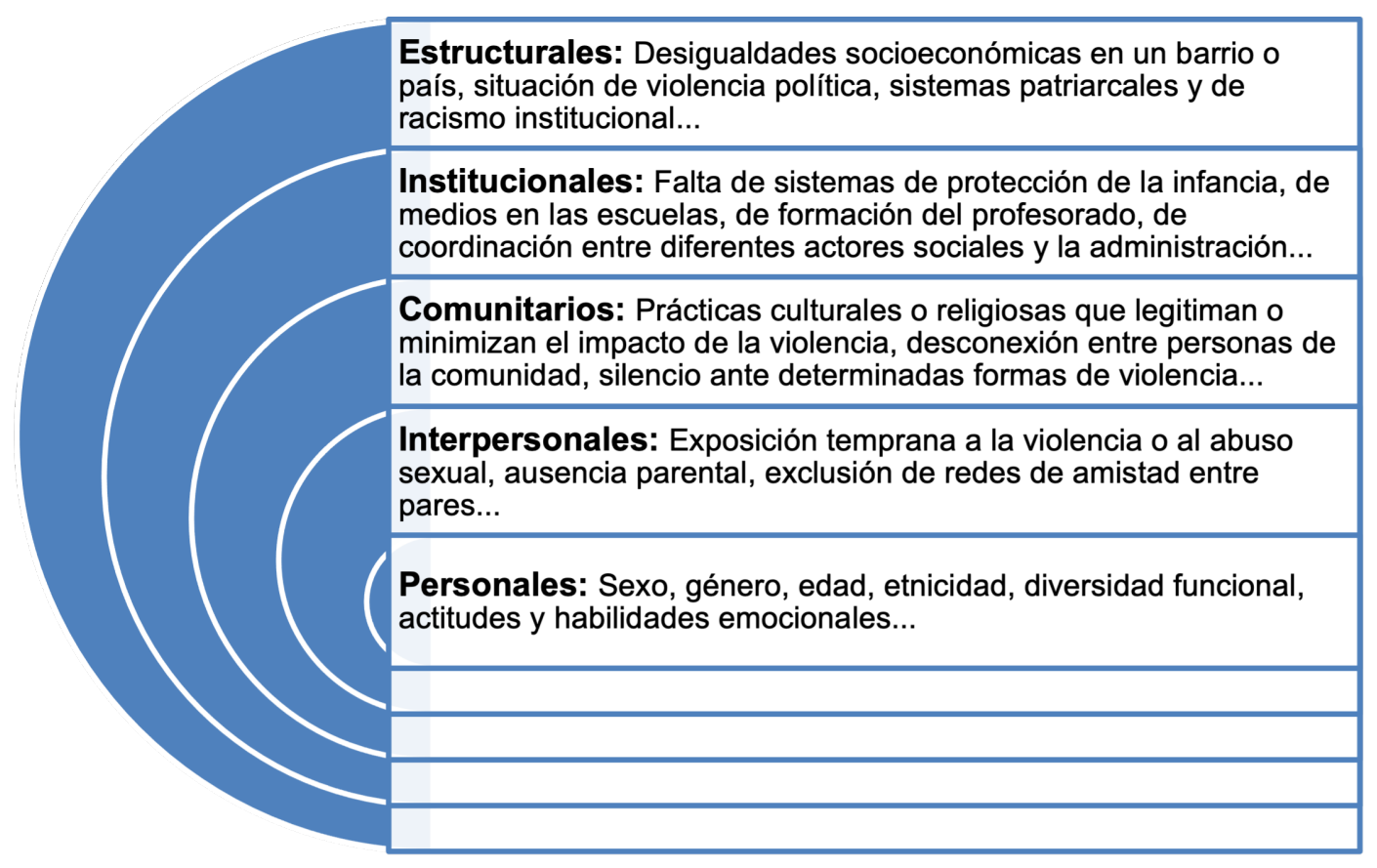

Figura. Factores causales de la violencia escolar. Fuente: Adaptación de Maternowska, Potts y Fry (2016, p. 2).

Uno de los factores causantes de la violencia y que afecta la institucionalidad escolar, por tanto, está relacionado con una formación insuficiente de los docentes, pero, considerando la gran cantidad de elementos implicados, ¿hasta qué punto puede decirse que la formación del profesorado es determinante? Esta no es más que una de las múltiples vías de acción sobre las cuales las políticas educativas podrían intervenir para reducir la violencia y favorecer la convivencia en las escuelas, al compartir la responsabilidad con las familias, la comunidad, el marco estructural.

Sin embargo, si bien la formación docente es un factor entre otros tantos, este es uno de los que son competencia de los ministerios y departamentos de educación. Desde un enfoque de derechos, es pertinente reclamar a la administración, titular de obligaciones, que asuma sus competencias en cuanto a formación de profesorado. Por ello, este artículo se centra en la formación docente. Maternowska, Potts y Fry subrayan que la formación docente en transformación de conflictos es imprescindible, pero no suficiente, y debe ser complementada con otras medidas en todos los niveles (estructural, institucional, comunitario, interpersonal y personal). 


\section{PINCELADAS TEÓRICAS Y CURRICULARES SOBRE CONVIVENCIA EN EL MARCO ESCOLAR}

\section{Tipologías teóricas de convivencia y abordaje del conflicto}

De la misma manera que existen diferentes comprensiones de la convivencia (FierroEvans y Carbajal-Padilla, 2019), hay también diversas comprensiones sobre cómo abordar los conflictos. Las estrategias para transformar estos conflictos suelen tipificarse en tres grandes escuelas: la de gestión de conflictos, en la que predomina la contención del enfrentamiento; la de resolución de conflictos, en la que se busca una solución a las causas de estos (Escuela de Harvard, Fisher y Ury, 1991; Johnson \& Johnson, 1996); y la de transformación de conflictos, que, además de resolver las causas, pone una atención especial en cuidar la relación entre las partes en conflicto (Galtung, 2003; Lederach, 2003).

Estas tres categorías han sido adaptadas al ámbito escolar por Cremin y Bewington (2017), que asocian los tres tipos de estrategias ante el conflicto a tres grados de promoción de la paz positiva en las escuelas: las orientadas a limitar las posibilidades de violencia directa en los centros escolares (gestión de conflictos/mantenimiento de la paz); las dirigidas a afrontar las causas de los conflictos (resolución de conflictos/establecimiento de la paz); y las que pretenden fomentar actitudes prosociales que cohesionen y cuiden la comunidad educativa (transformación de conflictos/construcción de paz), con un mayor componente formativo.

Aunque podemos considerar que las prácticas más efectivas de promoción de la convivencia en los centros educativos son las más comprehensivas y, por tanto, más afines a la transformación de conflictos y a la construcción de paz que a otras aproximaciones, este artículo tiene en cuenta los tres enfoques, dado que la realidad de los países estudiados es diversa y adopta estas distintas visiones.

En la práctica educativa, estas estrategias de intervención ante el conflicto se traducen en metodologías diversas. Estrategias para prevenir o atajar el acoso escolar y el ciberacoso, método Kiva, aplicación de protocolos de prevención de la violencia y del acoso escolar, entre otros, se centran en la contención (gestión del conflicto/ mantenimiento de la paz). Estrategias como la negociación de conflictos o los debates controvertidos se orientan a la resolución de las causas del conflicto (resolución de conflictos/establecimiento de la paz). Estrategias como la mediación entre iguales, la comunicación no violenta (Rosenberg, 2006), los círculos restaurativos, la educación emocional, el diálogo, la prevención (Burton, 1966; Cascón, 2001) y el aprendizaje cooperativo (Johnson, Johnson \& Holubec, 1994) hacen mayor hincapié en la mejora de la relación entre las partes (transformación de conflictos/construcción de paz).

Considerando la diversidad de estrategias y metodologías existentes en función del objetivo perseguido, deducimos que la formación docente en materia de convivencia y de conflictos es crucial a fin de que el profesorado conozca y sea capaz de aplicar esta diversidad de prácticas con criterio para valorar cuáles son más apropiadas para cada situación.

Aunque no todos los programas de formación de profesorado en conflictos y convivencia son igual de exitosos, innumerables estudios demuestran que, cuando el 
alumnado y el profesorado reciben formación en gestión, resolución o transformación de conflictos, los casos de comportamiento violento descienden (Johnson \& Johnson, 1996). Esto ocurre en especial cuando el profesorado consigue implementar medidas de modo global en toda la escuela, como proyectos de centro (Thapa et al., 2013). Otro estudio ha argumentado que el profesorado que se había preparado en estos temas durante los doce meses previos a ser encuestado ha reducido en un 9\% el tiempo lectivo que dedica a mantener el orden en las aulas (OCDE, 2013).

Más allá de estas valoraciones, que deben considerarse positivas, cabe reivindicar un papel del profesorado que supere la contención de la violencia o la mediación, y pueda centrarse en formar a personas (en gestión de las emociones, en comunicación efectiva y empática, en pensamiento complejo y creativo) con el propósito de que sean competentes para resolver sus conflictos por sí mismas.

\section{Marco legal internacional sobre la competencia de abordar el conflicto}

Las competencias para abordar los conflictos están reconocidas por varios documentos de organismos internacionales (OCDE, 2005; en el caso europeo: Consejo de Europa, 2016a; Comisión Europea, 2018). Desde 2018, además, las pruebas PISA de la Organización para la Cooperación y el Desarrollo Económicos (OCDE), aplicadas en 72 países del mundo al alumnado de 15 años, incorporaron una nueva dimensión a las encuestas para valorar las habilidades del alumnado asociadas a la "competencia global" para una mejor comprensión del mundo. Estas toman en consideración la comprensión de otros puntos de vista y cosmovisiones alternativas a las propias, o bien, la capacidad de interactuar con personas de otras culturas, mediante el diálogo, la curiosidad, la comunicación efectiva y la capacidad de resolver conflictos (OCDE, 2018).

La inclusión de tales competencias en las pruebas PISA probablemente fomente que los actores educativos -profesorado y también departamentos y ministerios de educación- las aborden de forma más significativa y transversal, hecho que, se presume, contribuirá a mejorar la convivencia escolar.

Por otro lado, es pertinente tener en cuenta que la nueva competencia global de las pruebas PISA se refiere al conflicto como un escollo a gestionar (OCDE, 2018), no como una oportunidad enriquecedora del proceso de aprendizaje.

A pesar de los aportes, ya clásicos, de Jacques Delors (1996), la traslación al currículo oficial de las competencias del aprender a vivir juntos es todavía muy inferior a lo que podría ser, de forma que los conocimientos, habilidades y actitudes relacionados con la resolución de conflictos distan de estar bien integrados de forma transversal o específica en los contenidos de aprendizaje.

\section{METOdOLOGía de ANÁLISIS}

Nuestro artículo sintetiza y actualiza las investigaciones de seis instituciones y diez investigadoras e investigadores durante dos años (2016-2018) en el marco del proyecto Educate (Noviolent Conflict Management for Teachers), financiado por la Unión Europea. Si bien para este artículo hemos actualizado datos y profundizado en algunas reflexiones, este trabajo no habría sido posible sin las aportaciones 
y reflexiones inestimables de Ivana Ćosić, Marjolein Delvou, Julie Fernandes, Ilse Hakvoort, Magda Hennebo, Arja Kostiainen, Katarina Kruhonja, Elena Passerini y Christian Renoux, coautores de algunas publicaciones citadas en este artículo y que fundamentan algunas de sus reflexiones.

La investigación se proponía analizar el estado de la cuestión en materia de formación del profesorado en transformación de conflictos. Tal diagnóstico, que concluye en una serie de recomendaciones, tiene una clara voluntad de incidir en las políticas y prácticas de formación de profesorado para que incorporen, de modo más sistemático, la preparación en estos temas y, por ello, puede enmarcarse en el enfoque sociocrítico.

De acuerdo con este enfoque, la investigación empleó metodologías cualitativas, de análisis comparado de estudios de casos, referentes a las políticas y las prácticas educativas de formación de profesorado en transformación de conflictos en cinco países europeos: Croacia, España, Francia, Italia y Suecia. Conforme al principio dialéctico de Edgar Morin (1995), que, con base en un planteamiento complejo, concibe la creación de conocimiento desde la observación de objetos de estudio diversos, la selección de países ha respondido a criterios de diversidad: así, incluimos países con diversidad de competencias educativas: descentralizada (España, Suecia)/ intermedia (Italia)/o centralizada (Croacia, Francia) (Eurydice, 2021) y con experiencias sociales distintas sobre violencia (Croacia como país en posguerra/Suecia como uno de los países con un índice de paz global más elevado), y poblaciones de alumnado y profesorado de tamaños muy distintos.

También hemos aplicado el enfoque de evaluación apreciativa, con el objetivo de reflexionar y formular recomendaciones partiendo de la identificación de buenas prácticas en cada contexto.

El campo de estudio ha incluido el análisis de la formación inicial, impulsado desde las universidades (grados de infantil, magisterio y maestrías de formación de profesorado de secundaria), y de la formación continuada, promovido a través de mecanismos públicos de formación continuada de profesorados, como centros de profesores y recursos en España, o bien, la Red Nacional de Escuelas Superiores del Profesorado y de la Educación en Francia, así como aquellas fomentadas por organizaciones del tercer sector especializadas en educación en el conflicto.

Conscientes de que la terminología utilizada en los diferentes contextos puede ser muy diversa de un país a otro, decidimos analizar las formaciones que incluyeran contenidos relacionados con los conflictos y la prevención del acoso escolar y el ciberacoso, y también con habilidades útiles para la transformación positiva de los conflictos (habilidades socioemocionales), educación para la paz en sentido amplio, comunicación no violenta (Rosenberg, 2006), y otros enfoques, aunque no mencionaran de forma explícita las palabras "conflicto" o "convivencia” en sus descripciones.

Para compensar esta definición tan amplia del objeto de estudio, definimos criterios básicos que debía cumplir una práctica formativa para ser considerada buena práctica: el hecho de que considerara el conflicto desde su perspectiva positiva y transformadora, y no únicamente como un problema; que tuviera una intención multiplicadora, es decir, que pretendiera formar al profesorado no solo para que interviniera en los conflictos en el aula de manera constructiva, sino también para formar al alumnado 
en esas competencias básicas para que, a su vez, pudiera aprender, de modo gradual, a afrontar y resolver estos conflictos por sí mismo; y que tuviera un enfoque lo más comprehensivo posible (whole school approach).

Las hipótesis iniciales partían de la asunción de que la formación del profesorado en competencias para la transformación de conflictos en el aula es insuficiente en número, y poco holística (con buenas prácticas puntuales, pero sin que llegue a constituir un plan fundamentado respecto de las necesidades de cada contexto, con planteamientos coherentes suficientes en cuanto a alcance y recursos provistos), como lo comprobamos. Aun así, la identificación de buenas prácticas nos permitió matizar esa hipótesis.

Para confirmar o refutar tales hipótesis, las principales categorías de análisis estudiadas se refieren a ¿qué presencia tiene la resolución de conflictos en los currículos, leyes y políticas educativas?, ¿es suficiente la actual formación universitaria y continuada del profesorado en conflictos y convivencia?, y ¿hasta qué punto se evalúa si estas políticas mejoran el clima de convivencia en las escuelas?

Los métodos de recogida y análisis de la información de los cinco estudios de casos consistieron en el análisis documental (de leyes educativas y currículos oficiales de cada país, syllabus de asignaturas universitarias de las carreras de educación, memorias de actividades públicas de formación de profesorado (impulsadas por la administración educativa o por actores del tercer sector, y fuentes secundarias) y una encuesta dirigida a profesorado universitario y entidades del tercer sector formadoras en temáticas que tienen que ver con el conflicto y la convivencia para conocer mejor sus prácticas.

Los principales criterios de selección de los documentos a examinar fueron la accesibilidad y comparabilidad (disponibilidad de documentos equiparables en los cinco países estudiados); la relevancia (relativa a contenidos de formación de profesorado), la diversidad del origen: documentos emitidos por los parlamentos (leyes educativas), por las universidades (descripciones de carreras universitarias, syllabus de asignaturas) y por organismos de formación continuada (memorias de formación) y la autenticidad (prioridad al análisis de documentos primarios).

El análisis cualitativo de la documentación de cada caso se efectuó mediante el análisis de contenidos a través de un software especializado, con categorías definidas de modo inductivo (ver tabla 1). En las categorías en las que era pertinente, también distinguimos el nivel educativo (primaria, secundaria y grado universitario y máster de profesorado) o si se trataba de formación inicial (universitaria) o continuada.

Tabla 1. Codificación del análisis cualitativo

\begin{tabular}{|c|c|c|}
\hline Grupo de código & Código & Definición \\
\hline Políticas educativas & Pol_Ed & $\begin{array}{c}\text { Políticas educativas históricas que hayan hecho referencia } \\
\text { a la transformación de conflictos }\end{array}$ \\
\hline Normativización & Norm_ & $\begin{array}{c}\text { Mención a competencias de transformación de conflictos o } \\
\text { educación emocional de los currículos y leyes educativas }\end{array}$ \\
\hline Normativización & Norm_struct & $\begin{array}{c}\text { Mención a mecanismos estructurales de transformación } \\
\text { de conflictos en los centros educativos }\end{array}$ \\
\hline Organigrama & Org & $\begin{array}{c}\text { Descripción de los principales actores educativos res- } \\
\text { ponsables de definir las políticas educativas, promover la } \\
\text { formación docente y valorar la calidad educativa }\end{array}$ \\
\hline
\end{tabular}

Barbeito. Imprescindible, insuficiente, incoherente e instrumental: formación docente para aprender a convivir Sinéctica 57 www.sinectica.iteso.mx 


\begin{tabular}{|c|c|c|}
\hline Formación docente & FD_contenidos & Competencias promovidas en las formaciones docentes \\
\hline Formación docente & FD_met & Metodologías mencionadas en las formaciones \\
\hline Formación docente & FD_Cred & Número de créditos o número de horas de las formaciones \\
\hline Formación docente & FD_Obl & $\begin{array}{c}\text { Obligatoriedad o carácter optativo de la asignatura uni- } \\
\text { versitaria u obligatorio o bajo demanda del profesorado } \\
\text { de la formación continuada }\end{array}$ \\
\hline Formación docente & FD_Bibl & $\begin{array}{c}\text { Bibliografía citada en los syllabus y descripciones de las } \\
\text { formaciones }\end{array}$ \\
\hline Indicadores & Ind & $\begin{array}{c}\text { Indicadores relativos al clima de convivencia, al acoso } \\
\text { escolar y ciberacoso, a la violencia y a los conflictos en el } \\
\text { ámbito escolar }\end{array}$ \\
\hline
\end{tabular}

En el caso de la sistematización de buenas prácticas de formación docente, las categorías abordadas fueron sus objetivos, metodologías, proceso de implementación, retos y oportunidades generadas por el contexto donde se desarrollan, y sus resultados e impactos.

A pesar de regirse con base en orientaciones educativas comunes recomendadas por la Comisión Europea, la comparación de cinco escenarios con grandes diferencias en las ratios de profesorado por alumno o alumna, en las competencias priorizadas para los diferentes actores educativos públicos y privados y las diferencias en las políticas educativas heredadas en cada país (Hakwoort et al., 2018), presentó límites. Otra dificultad del trabajo fue la falta de acceso a algunos datos que fueran suficientemente significativos en todos los países. Aun así, como exponemos a continuación, el análisis comparado de las categorías de estudio ya descritas aporta elementos valiosos para reflexionar sobre las políticas de formación de profesorado en conflicto y convivencia.

\section{REGULACIONES Y PRÁCTICAS DE FORMACIÓN DOCENTE}

Siguiendo la máxima de que "lo que existe es posible" tantas veces defendida por la educadora por la paz Elise Boulding, la investigación pretende identificar buenas prácticas de los países para orientar la mejora de las políticas de formación docente referentes al conflicto y la convivencia. Por ello, en el siguiente apartado explicamos primero las políticas y prácticas actuales en los casos estudiados y, en seguida, formulamos recomendaciones que refuercen tales políticas y prácticas.

\section{Observaciones}

En cuanto a las observaciones, el análisis se ha centrado en lo que está establecido por normativa sobre competencias relativas al conflicto y la convivencia para contrastarlo a continuación con la situación en la práctica de la formación docente, ya sea inicial o continuada; acabamos analizando el grado de autoevaluación de esas políticas y prácticas de promoción de la convivencia escolar.

- Leyes y políticas de formación docente en conflicto y convivencia

Para contextualizar la comparación de políticas de formación de profesorado en convivencia escolar, el estudio analiza hasta qué punto las leyes educativas (de primaria, secundaria y ámbito universitario) y las regulaciones de currículo escolar 
identifican las competencias relativas al conflicto como importantes. Aunque en los currículos de primaria y secundaria las competencias consideradas clave son las del alumnado y no las del profesorado, estas también fueron tenidas en cuenta, al asumir que, para que el profesorado forme al alumnado en esas competencias, debe haberse preparado a sí mismo previamente.

En varios contextos se han identificado prácticas específicas de formación de profesorado que, sin estar reguladas por ley, pretenden reforzar las competencias del profesorado para abordar los conflictos de forma positiva y mejorar la convivencia escolar y transmitir esto a su alumnado.

Tabla 2. Comparación de regulaciones y políticas sobre formación de profesorado en conflicto y convivencia

\begin{tabular}{|c|c|c|}
\hline & $\begin{array}{l}\text { Regulaciones legales significativas en mate- } \\
\text { ria de conflictos y convivencia }\end{array}$ & $\begin{array}{c}\text { Políticas educativas significativas de } \\
\text { formación de profesorado en conflictos y } \\
\text { convivencia }\end{array}$ \\
\hline Croacia & $\begin{array}{l}\text { La Ley sobre Educación Primaria y Secun- } \\
\text { daria (2008/2014) no menciona explícita- } \\
\text { mente la resolución de conflictos como una } \\
\text { competencia clave }\end{array}$ & $\begin{array}{l}\text { Existen diferentes planes de formación del } \\
\text { alumnado en transformación de conflictos, } \\
\text { pero no de formación de profesorado }\end{array}$ \\
\hline España & $\begin{array}{c}\text { La actual Ley Orgánica de Modificación } \\
\text { de la Ley Orgánica de Educación (2020) } \\
\text { menciona entre sus objetivos (artículo } 1^{\text {o }} \text { ) } \\
\text { la convivencia, la prevención de conflictos y } \\
\text { su resolución pacífica, la no violencia frente } \\
\text { al acoso escolar, ciberacoso, toda forma de } \\
\text { maltrato, abuso sexual, violencia o discri- } \\
\text { minación. Refuerza leyes anteriores que ya } \\
\text { mencionaban objetivos parecidos } \\
\text { La Ley Orgánica de Universidades (Ley } \\
\text { 6/2001) no define los contenidos que deben } \\
\text { tratarse en las universidades }\end{array}$ & $\begin{array}{l}\text { El Plan para la Promoción y la Mejora de la } \\
\text { Convivencia Escolar (desde 2006) y el Plan } \\
\text { Estratégico para la Convivencia Escolar } \\
\text { (2016-2020) destacan la necesidad de for- } \\
\text { mar al profesorado en dichos temas. Estos, } \\
\text { sin embargo, están dotados de pocos fondos } \\
\text { y dependen de que los centros los soliciten } \\
\text { (oferta de cursos sobre transformación de } \\
\text { conflictos condicionados a que haya deman- } \\
\text { da por parte de las escuelas) }\end{array}$ \\
\hline Francia & $\begin{array}{l}\text { La definición común de conocimientos, } \\
\text { de competencias y cultura (Ministère de } \\
\text { l’Éducation Nationale, 2015) introdujo por } \\
\text { primera vez la competencia de gestión de } \\
\text { conflictos en el currículo escolar (Decreto nº } \\
\text { 2015-372) }\end{array}$ & $\begin{array}{l}\text { La Ley de Educación o Ley Peillon (2013) es- } \\
\text { tablece que los INSPE (organismos públicos } \\
\text { de formación inicial de profesorado) deben } \\
\text { ofrecer cursos de resolución no violenta de } \\
\text { conflictos (oferta obligatoria) }\end{array}$ \\
\hline Italia & $\begin{array}{l}\text { La Ley } 107 / 2015 \text { no menciona explícita- } \\
\text { mente la resolución de conflictos como una } \\
\text { prioridad educativa, pero sí la educación } \\
\text { para la paz, el respeto de las diferencias y el } \\
\text { diálogo intercultural }\end{array}$ & $\begin{array}{c}\text { La Ley } 107 / 2015 \text { provee de fondos al } \\
\text { profesorado para su formación individual, } \\
\text { que puede incluir temas de resolución } \\
\text { de conflictos entre otros, si así lo solicita } \\
\text { el profesorado (oferta condicionada a la } \\
\text { demanda) }\end{array}$ \\
\hline & $\begin{array}{l}\text { La Ley Sueca de Educación (2010) no señala } \\
\text { las competencias de gestión de conflictos en } \\
\text { el ámbito escolar }\end{array}$ & $\begin{array}{l}\text { La formación de profesorado se impulsa } \\
\text { desde la formación universitaria a partir de } \\
2011 \text { como una asignatura }\end{array}$ \\
\hline Suecia & $\begin{array}{l}\text { La regulación Educational Science Core } \\
\text { (2011) de competencias del profesorado } \\
\text { establece que la formación docente debe } \\
\text { incluir ocho áreas de aprendizaje, una de las } \\
\text { cuales es "gestión de conflictos y lideraje" }\end{array}$ & $\begin{array}{l}\text { No existen programas específicos de for- } \\
\text { mación continuada de profesorado sobre } \\
\text { conflictos, aunque este tiene la posibilidad } \\
\text { de elegirlos entre otros temas (oferta condi- } \\
\text { cionada a la demanda) }\end{array}$ \\
\hline $\begin{array}{l}\text { Órganismos } \\
\text { inter-nacionales }\end{array}$ & $\begin{array}{c}\text { Tanto la definición y selección de competen- } \\
\text { cias (DeSeCo) de la OCDE como el plan de } \\
\text { acción para construir sociedades inclusivas } \\
\text { del Consejo de Europa (2016b) precisan la } \\
\text { resolución de conflictos como una compe- } \\
\text { tencia clave del alumnado }\end{array}$ & $\begin{array}{l}\text { No promueven programas específicos de } \\
\text { formación de profesorado }\end{array}$ \\
\hline
\end{tabular}

Fuente: Actualización de Barbeito et al., 2018, p. 65.

Barbeito. Imprescindible, insuficiente, incoherente e instrumental: formación docente para aprender a convivir Sinéctica 57 www.sinectica.iteso.mx 
En referencia a la definición de competencias del alumnado en primaria y secundaria en las leyes educativas, solo dos de los países estudiados (España y Francia) explican que la resolución de conflictos es una competencia clave. En ambos casos se señalan estas competencias en forma de objetivo educativo genérico, pero sin ser desarrollado en las áreas o asignaturas. En Croacia y Suecia, las leyes educativas identifican competencias que podrían considerarse cercanas, como la no discriminación o las habilidades para la democracia, o bien, la prevención de la violencia, pero sin mencionar el conflicto.

En cuanto a las competencias del profesorado, tan solo Suecia identifica como clave la resolución de conflictos en un documento legal que la reconoce como una de las ocho áreas de formación inicial del profesorado.

En Francia (para primaria y secundaria) y Suecia (para la formación de profesorado), la inclusión de la educación para transformación de conflictos en la formación de profesorado se debe, en parte, a la existencia de campañas de presión de organizaciones ciudadanas durante más de diez años, que fueron luego recogidas por partidos o actores políticos. En España, el desarrollo del Plan Estratégico de Convivencia Escolar se activó tras el grave suicidio de un menor que había padecido acoso escolar.

Analizando los cinco casos en conjunto, no podemos considerar que las competencias relativas a la convivencia y la transformación de conflictos tenga un reconocimiento unánime en las políticas educativas. Por otro lado, cabe aclarar que el reconocimiento de esas competencias en las leyes educativas u otras regulaciones escritas no son garantía de mejores prácticas de formación de profesorado en conflictos y convivencia en la práctica. Incluso en aquellos países en que las competencias de transformación de conflictos del alumnado o del profesorado quedan reconocidas por las leyes educativas o los currículos, la formación de profesorado en abordaje constructivo del conflicto y promoción de la convivencia, en la práctica, no se garantiza de modo generalizado.

Las leyes educativas y los currículos oficiales del alumnado y del profesorado deberían reconocer las competencias relacionadas con el aprender a vivir juntos, pero su aplicación efectiva requiere diversas medidas complementarias. La formación del profesorado es solo una de las medidas existentes para que el alumnado pueda obtener estos aprendizajes. Otras medidas cruciales por normativizar serían, por ejemplo, el despliegue de estas competencias de las diferentes áreas de estudio y a lo largo de las progresivas etapas educativas (Massip et al., 2018) en el aula, y velar porque, en los centros escolares, las normas, sanciones (restaurativas) y canales de participación sean coherentes con este enfoque, y estén recogidas en los planes de mejora de la convivencia en los centros educativos. Estas medidas son necesarias y complementarias y, por tanto, compatibles con la formación docente.

- Formación inicial y continuada de profesorado

Independientemente de que los currículos y las leyes educativas identifiquen los conocimientos, habilidades y actitudes relacionadas con el abordaje de conflictos como competencias clave, o no, en la práctica se han encontrado experiencias de formación de profesorado en todos los países estudiados. ¿Hasta qué punto son estas prácticas mayoritarias y permiten llegar a una proporción significativa de profesorado? 
Partiendo del supuesto de que saber afrontar conflictos es una competencia clave del profesorado, nuestro análisis pretende distinguir la formación universitaria inicial -que debería permitir llegar a la totalidad del profesorado- de la formación continuada o a lo largo de la vida que, si bien ayuda a capacitar al profesorado en activo, suele llegar a una proporción muy inferior de docentes.

Tabla 3. Análisis comparativo de la formación inicial y continuada del profesorado en transformación de conflictos

\begin{tabular}{|c|c|c|}
\hline & $\begin{array}{l}\text { Formación inicial en transformación de } \\
\text { conflictos en los grados de pedagogía }\end{array}$ & $\begin{array}{l}\text { Formación continuada del profesorado en } \\
\text { transformación de conflictos }\end{array}$ \\
\hline Croacia & $\begin{array}{l}\text { Existen algunas asignaturas optativas en } \\
\text { varios grados de pedagogía -más presentes } \\
\text { en formación de profesorado de educación } \\
\text { infantil y primaria que de secundaria }\end{array}$ & $\begin{array}{l}\text { Impulsada por los canales oficiales de } \\
\text { formación de profesorado del Ministerio de } \\
\text { Educación (ETTA) } \\
\text { Formadores individuales y organizaciones } \\
\text { del tercer sector reportan la dificultad de } \\
\text { colaborar con la agencia ETTA y ofrecer sus } \\
\text { cursos a través del canal oficial }\end{array}$ \\
\hline España & $\begin{array}{l}\text { Algunas asignaturas optativas identificadas, } \\
\text { grados de pedagogía, con grandes oscilacio- } \\
\text { nes entre universidades (de cero hasta ocho } \\
\text { asignaturas relacionadas, en función de la } \\
\text { universidad) } \\
\text { El máster de formación para profesorado } \\
\text { de secundaria no contiene asignatura espe- } \\
\text { cífica alguna }\end{array}$ & $\begin{array}{l}\text { Impulsada tanto por formadores individua- } \\
\text { les y organizaciones del tercer sector como } \\
\text { por los canales oficiales de formación de } \\
\text { profesorado del Ministerio de Educación o } \\
\text { departamentos regionales (Centro de Recur- } \\
\text { sos y Profesores) }\end{array}$ \\
\hline Francia & $\begin{array}{l}\text { No se han identificado asignaturas en los } \\
\text { grados de infantil, primaria y secundaria } \\
\text { El máster para ser profesor/a de primaria } \\
\text { o secundaria, impartidos por los institutos } \\
\text { nacionales superiores del profesorado y de } \\
\text { la educación (INSPE) incluye contenidos de } \\
\text { prevención de la violencia y resolución no } \\
\text { violenta de los conflictos }\end{array}$ & $\begin{array}{l}\text { Impulsada tanto por formadores individua- } \\
\text { les y organizaciones del tercer sector como } \\
\text { por los canales oficiales de formación de } \\
\text { profesorado del Ministerio de Educación } \\
\text { (INSPE, que se encarga no solo de la forma- } \\
\text { ción inicial, sino también de la formación } \\
\text { continuada) }\end{array}$ \\
\hline Italia & $\begin{array}{l}\text { No se han identificado asignaturas en los } \\
\text { grados de infantil, primaria y secundaria }\end{array}$ & $\begin{array}{l}\text { Impulsada por formadores individuales y } \\
\text { organizaciones del tercer sector fuera de los } \\
\text { canales oficiales del Ministerio de Educación }\end{array}$ \\
\hline Suecia & $\begin{array}{l}\text { Todas las universidades deberían ofrecer } \\
\text { formación obligatoria en "gestión de con- } \\
\text { flictos y liderazgo" en todos los grados de } \\
\text { infantil, primaria y secundaria. Se observa } \\
\text { que la aplicación de esta regulación es de un } \\
\text { máximo del 74\% de las asignaturas }\end{array}$ & $\begin{array}{l}\text { Impulsada por universidades, formadores } \\
\text { individuales y organizaciones del tercer sec- } \\
\text { tor por los canales oficiales de formación de } \\
\text { profesorado del Ministerio de Educación }\end{array}$ \\
\hline $\begin{array}{l}\text { Organismos } \\
\text { internacionales }\end{array}$ & $\begin{array}{l}\text { No tienen competencias de formación inicial } \\
\text { de profesorado }\end{array}$ & $\begin{array}{l}\text { Formación continuada de profesorado im- } \\
\text { pulsada por algunas instituciones (Consejo } \\
\text { de Europa) de forma puntual }\end{array}$ \\
\hline
\end{tabular}

Fuente: Actualización de Barbeito et al., 2018, p. 65.

La formación inicial (universitaria) de profesorado en competencias relacionadas con la transformación de conflictos es poco habitual. La notable excepción la constituye Suecia, donde, según la normativa, todos los grados de educación ofrecen contenidos de "gestión de conflictos y liderazgo". Incluso en este país, único en considerar obligatorio este contenido en la formación de profesorado, se ha observado que, en la práctica, al menos cinco de las 19 universidades que cursan grados de pedagogía apenas mencionan el conflicto en los objetivos pedagógicos y en la bibliografía de los syllabus (Hakvoort y Kostiainen, citados en Hakwoort et al., 2018). 
Estos contenidos podrían estar incluidos de forma transversal, pero, aun así, su ausencia de los syllabus apunta a que no deben ser significativos. De ese modo, ni en la práctica identificada más extensiva se puede considerar que todo el futuro profesorado recibe una formación universitaria sobre competencias para afrontar los conflictos y promover la convivencia en la escuela. En Croacia, Francia, Italia y las tres regiones analizadas de España, pocos grados universitarios ofrecen asignaturas de transformación de conflictos, y en la gran mayoría de casos, estas son optativas (Barbeito et al., 2018).

\section{- Entre las fortalezas}

En cuanto a la formación continuada de profesorado, los contenidos relacionados con los conflictos y la convivencia son minoritarios: en 2016, un $2.4 \%$ de los cursos de formación continuada tenían que ver con el conflicto y la convivencia en España (datos del MECD, citados por Barbeito, en Hakwoort et al., 2018). En todos los contextos, la información acerca de la formación continuada está tan disgregada (en especial en Italia) o incompleta (Suecia y España) que no facilita al profesor conocer la totalidad de la oferta que está a su disposición.

Aunque ha resultado muy difícil cuantificar la presencia de las formaciones de profesorado en la formación inicial y continuada de los cinco países debido a la dispersión de la información, hemos podido constatar que, en la educación universitaria, existen más asignaturas relacionadas con el conflicto y la convivencia en los grados para convertirse en docente de infantil y primaria que para docentes de secundaria. También, existe más oferta impulsada por actores del sector informal que del formal.

En la mayoría de los países (Croacia, España, Italia, Francia), la formación de profesorado en materia de conflictos se aborda sin indicaciones específicas de contenidos o prioridades marcadas por la administración. Por ello, se ofrecen formaciones desde enfoques más restringidos (contención), como la prevención de la violencia, el acoso escolar y el ciberacoso, gestión de conflictos hasta enfoques de paz positiva (transformación), como la educación para la paz y la convivencia, pasando por la comunicación no violenta, la educación emocional o la cultura de paz.

En Suecia, sin embargo, la Agencia Nacional Sueca de Educación recomienda que las formaciones de profesorado en conflicto y convivencia, ya sea inicial o continuada, se imparta desde la perspectiva crítica de las normas (normkritik), que visibiliza y problematiza las normas y convenciones que reproducen las desigualdades y las estructuras de poder. Lejos de centrarse únicamente en las competencias del alumnado para contener el acoso o transformar conflictos, esta perspectiva invita a reflexionar sobre la violencia estructural y el currículo oculto de las instituciones educativas vinculados a las normas sociales y culturales dominantes (Hakwoort et al., 2018). Si bien el enfoque impulsado en Suecia parece estructural y holístico para fomentar la transformación de conflictos y la promoción de la convivencia en los centros, la diversidad de perspectivas teóricas y metodológicas de las demás formaciones también se considera como una riqueza, reflejo de la variedad de metodologías existentes.

La percepción del profesorado de la formación docente en transformación de conflictos es ambivalente: si bien la evaluación de la mayoría de los cursos analizados mostraba un grado alto de satisfacción del alumnado, la percepción sobre la importancia de estos 
contenidos no es similar. Mientras que en algunas asignaturas la evaluación del alumnado destaca su aplicabilidad y deplora que no sean contenidos obligatorios (Barbeito, citado en Hakwoort et al., 2018), en otros casos, como mencionaron informantes clave de universidades croatas, el futuro profesorado formado en conflictos y convivencia en la universidad valora positivamente los aprendizajes como útiles y aplicables, pero los considera como un conocimiento de menor relevancia que saberes de otras áreas (Ćosić, citado en Hakwoort et al., 2018). Cabría valorar la necesidad de reforzar el corpus teórico de esa enseñanza, asociado a paradigmas pedagógicos existentes.

De acuerdo con lo observado, existe un gran potencial de mejora en la formación universitaria del profesorado para garantizar que todo el profesorado tenga acceso a la formación inicial en materia de conflictos y convivencia, sea introduciendo más asignaturas o convirtiéndolas en obligatorias. A la vez, podría ser de utilidad facilitar la información de los cursos de formación continuada sobre conflicto y convivencia disponibles para contrastarlas con las demandas del profesorado.

- Seguimiento del impacto de las políticas de convivencia

La formación de profesorado en transformación de conflictos y convivencia debería aspirar a que el profesorado aprenda este proceso de manera constructiva (objetivo instrumental para la docencia) y también que el alumnado mejore estas mismas habilidades para poder abordar, por sí mismo, los conflictos de modo no violento (objetivo formativo del alumnado). Si ambos objetivos se cumplieran, podríamos esperar que el clima de convivencia en las escuelas fuera óptimo o, cuanto menos, no empeorara.

El análisis de los modelos de los diferentes países ha permitido identificar que la recogida de datos se hace desde una visión global, con información oficial de la administración o por parte de otros actores.

Tabla 4. Comparación de formas de recogida de datos para el seguimiento de las políticas de convivencia

\begin{tabular}{|c|c|c|}
\hline & $\begin{array}{c}\text { Recogida de datos oficiales sobre conflictos y } \\
\text { convivencia escolar }\end{array}$ & Recogida de datos por otras instituciones \\
\hline Croacia & Ninguna sistematización pública de datos & $\begin{array}{c}\text { Evaluación de programas específicos como } \\
\text { Stop Violence among Children (2003-2011), } \\
\text { del Unicef, que formó a profesorado de más } \\
\text { de } 300 \text { escuelas }\end{array}$ \\
\hline \multirow{2}{*}{ España } & \multirow{2}{*}{$\begin{array}{l}\text { El Plan para la Promoción y Mejora de la Con- } \\
\text { vivencia Escolar (2006) preveía la creación de } \\
\text { un observatorio estatal, pero este todavía está } \\
\text { inactivo } \\
\begin{array}{c}\text { Algunas regiones tienen observatorios regio- } \\
\text { nales de violencia/convivencia escolar }\end{array}\end{array}$} & $\begin{array}{l}\text { La fundación Anar recoge datos sobre acoso } \\
\text { escolar. El sindicato ANPE reúne datos } \\
\text { sobre violencia hacia el profesorado }\end{array}$ \\
\hline & & $\begin{array}{c}\text { convivencia, pero esta información no tiene } \\
\text { por qué ser pública ni se analiza pública- } \\
\text { mente a nivel regional o estatal }\end{array}$ \\
\hline Francia & $\begin{array}{l}\text { Sistematización de datos basados en encues- } \\
\text { tas al alumnado sobre victimización y convi- } \\
\text { vencia (Enquête Nationale de Climat Scolaire } \\
\text { et Victimation) cada dos a cuatro años }\end{array}$ & $\begin{array}{l}\text { El Observatorio de la Violencia en las Escue- } \\
\text { las es una organización que promueve la re- } \\
\text { flexión teórica sobre violencia y convivencia } \\
\text { escolar (no sistematiza datos cuantitativos) }\end{array}$ \\
\hline Italia & Ninguna sistematización pública de datos & $\begin{array}{l}\text { Evaluaciones de programas específicos de } \\
\text { formación de profesorado }\end{array}$ \\
\hline
\end{tabular}

Barbeito. Imprescindible, insuficiente, incoherente e instrumental: formación docente para aprender a convivir Sinéctica 57 www.sinectica.iteso.mx 


\begin{tabular}{|c|c|c|}
\hline Suecia & Ninguna sistematización pública de datos & $\begin{array}{l}\text { La Ley de Educación y la Ley sobre Discri- } \\
\text { minación obligan a las escuelas a siste- } \\
\text { matizar información anualmente acerca } \\
\text { de la situación del alumnado (seguridad, } \\
\text { discriminación, entre otros temas) }\end{array}$ \\
\hline $\begin{array}{c}\text { Organismos } \\
\text { internacionales }\end{array}$ & $\begin{array}{l}\text { Los países que así lo desean envían informes } \\
\text { de cumplimiento de la recomendación sobre } \\
\text { la educación para la comprensión interna- } \\
\text { cional, la cooperación y la paz, y la educación } \\
\text { relacionada con los derechos humanos y las } \\
\text { libertades fundamentales a la Organización } \\
\text { de las Naciones Unidas para la Educación, la } \\
\text { Ciencia y la Cultura } \\
\text { (Unesco, 2017), con información del grado de } \\
\text { cumplimiento de las recomendaciones }\end{array}$ & $\begin{array}{c}\text { Encuestas cuadrienales Health Behaviour } \\
\text { in School-Aged Children, Cross-National } \\
\text { Surveys (sobre acoso escolar, ciberacoso y } \\
\text { peleas) } \\
\text { Observatorio Internacional de Violencia } \\
\text { en las Escuelas (con investigación teórica } \\
\text { sobre violencia y convivencia escolar) (no } \\
\text { sistematiza datos cuantitativos) }\end{array}$ \\
\hline
\end{tabular}

Fuente: Actualización de Barbeito et al., 2018, p. 65.

En general, la sistematización y el seguimiento de la realidad en los centros es insuficiente para un correcto análisis y evaluación de las políticas y prácticas de convivencia en los centros escolares. Francia es el único país que analiza cuantitativa y cualitativamente el clima de convivencia, y sus estudios aportan muchas pistas para orientar las políticas de convivencia. Croacia e Italia no impulsan ninguna iniciativa para la recogida de datos en las escuelas. En España, aunque se aprobó la creación de un observatorio estatal de convivencia escolar en 2006, este sigue sin funcionar y ha sido suplido por varios observatorios regionales. En Suecia y en España se requiere a las escuelas que valoren la discriminación y la convivencia en su centro, sin llegar a examinar esta información para orientar las políticas de convivencia.

En los casos en que, desde los ministerios o departamentos de educación, se promueve algún tipo de análisis de datos sobre la convivencia, los indicadores más frecuentes se refieren al clima de convivencia en la escuela; el grado de (in)seguridad percibido en el centro escolar y en los alrededores de este; la valoración de las relaciones (entre alumnado, alumnado-profesorado, entre profesorado, con el personal no docente, con la comunidad); el clima que facilita/dificulta la docencia; la percepción de justicia de las sanciones; o la identificación de normas que podría marginar a ciertos alumnos/as (Díaz-Aguado, Martínez Arias y Martín Babarro, 2010; Rosenwald, 2020). En el caso francés y español se trata de encuestas de percepción de diferentes actores educativos (estudiantes en Francia, y estudiantes, profesorado y dirección en España), mientras que en Suecia son informes elaborados por las direcciones de los centros escolares.

Estos indicadores tienen una orientación "finalista", que pretende describir la situación de conflicto y convivencia en un momento determinado en el sistema educativo. No tienen en cuenta aspectos relativos al proceso de aprendizaje de las competencias asociadas a los conflictos y la convivencia, como podrían ser preguntas que permitan valorar el grado de mejora en la capacidad del profesorado de intervenir en el conflicto de forma positiva, la capacidad del alumnado de intervenir en el conflicto de manera positiva, o de actuar para atajar casos de acoso escolar.

La recolección y el análisis de datos macrosociales resultan útiles para la evaluación de la efectividad y el impacto de las medidas de mejora de la convivencia en los 
centros (entre las cuales está la formación docente). Es útil, por tanto, para evaluar la efectividad de las políticas públicas al respecto. Sin embargo, en este artículo resulta en especial interesante la demanda a las escuelas de que elaboren informes de valoración de la implementación del Plan de Convivencia Escolar (España) o de las posibles discriminaciones en el centro (Suecia). Así lo promueve también el Centro Psicopedagogico per la Pace e la Gestione dei Conflitti en Italia, que invita al profesorado a mantener un cuaderno del conflicto en el aula con un registro de los hechos para analizarlo después. Si se dispone de las condiciones para efectuar estos informes a conciencia, pueden ser un excelente ejercicio de práctica reflexiva del equipo docente respecto a su rol de promotor/a de la convivencia en sus centros.

Finalmente, en cuanto a los datos para el seguimiento del impacto de las políticas de convivencia, y retomando los estudios comparativos internacionales reflejados testimonialmente en las gráficas 1 y 2 , sería pertinente preguntarse si mayores o menores índices de peleas, acoso y ciberacoso en los países analizados se corresponden con mejores o peores leyes, políticas y prácticas de formación de profesorado. Aunque un análisis riguroso de esta correlación supera el alcance de este artículo, no parece posible argumentar una relación consistente entre la existencia de modelos de formación de profesorado más sólidos (en el caso de Suecia y Francia) y unos índices bajos de victimización.

Esta observación permitiría concluir que, aunque existen buenas prácticas que sería recomendable replicar en otros contextos, ningún país destaca por tener políticas de formación docente suficientemente holísticas y efectivas de promoción de la convivencia como para impactar a la baja los índices de victimización.

\section{RECOMENDACIONES}

De acuerdo con las observaciones de cada caso, y ante la necesidad de reforzar la formación docente en transformación de conflictos, hemos identificado cuatro criterios orientadores, referentes a los contenidos, los actores clave, las metodologías y el nivel de aplicación (Delvou et al., 2018).

Acerca de los contenidos, y aunque resulta provechosa la diversidad de enfoques, es importante resaltar que la aproximación al conflicto debe ser positiva, al considerar el conflicto como una oportunidad de aprendizaje transformativo más que un problema y, a la vez, sin olvidar que el objetivo último de la transformación de conflictos va más allá de su resolución puntual de las diferencias, sino que debería aspirar, además, a mejorar las relaciones entre todas los miembros de la comunidad escolar.

La formación de profesorado debe tener por objetivo empoderar a los principales actores, de manera que, por un lado, dote al profesorado, entre otros actores educativos (educadores de patio, extraescolares), de estrategias, habilidades y recursos que le permitan transformar el conflicto y convertirlo en un oportunidad de crecimiento personal y colectivo; además, por otro lado, que capacite al alumnado a resolver conflictos por sí mismo. El profesorado no debe ser el único responsable de gestionar todos los conflictos en el aula, y puede aligerar así una de sus cargas.

Las metodologías, en tercer lugar, deben ofrecer a los educandos/as la oportunidad de experimentar el conflicto, interactuar y ponerse en la piel de las demás personas. Por ello, es recomendable usar métodos de diálogos controvertidos como 
base para apreciar la diversidad, promover actividades para experimentar que es posible encontrar soluciones yo gano-tú ganas, y utilizar ejemplos prácticos y ejercicios basados en problemas o incidentes reales.

Finalmente, tener en cuenta que la formación del profesorado es insuficiente si no cuenta con el apoyo del resto del equipo docente y, por ello, adoptar un enfoque estructural de toda la escuela (whole-school approach), y que se propague en círculos excéntricos, a nivel individual, de clase, de centro, de comunidad y mundial. En el ámbito individual, el profesorado debe ser consciente de su posición como modelo a seguir, y de la importancia de la coherencia personal en todos sus actos. En el otro extremo, la práctica de la transformación de conflictos desafía a todo el sistema escolar, en la medida en que los mecanismos de gestión de conflictos deben introducirse de modo estructural y sostenible en la organización de centro.

De acuerdo con los criterios mencionados, que pretenden pasar de medidas de contención de la violencia a un enfoque más constructivo, holístico, sostenible y de empoderamiento, recomendamos medidas para reforzar la formación del profesorado (ver tabla 5).

Tabla 5. Recomendaciones para reforzar la formación del profesorado en transformación de conflictos

\begin{abstract}
- Cambiar de enfoque, superando la prevención de la violencia y la gestión de conflictos a favor de un concepto y una práctica más amplios de transformación de conflictos no violentos y de convivencia pacífica

- Establecer leyes educativas que hagan explícito que la transformación de conflictos es una competencia clave, tanto del alumnado como del profesorado

- Sistematizar datos sobre conflictos y métodos de afrontamiento para que el efecto de la capacitación en transformación de conflictos pueda ser monitoreada y evaluada tanto a nivel escolar como estatal

- Reconocer de forma más consistente el papel del profesorado en la creación de entornos escolares cooperativos y constructivos, incluyendo planes de desarrollo personal bien definidos, planes de acción profesional y seguimiento, un apoyo gubernamental sostenido para la transformación de conflictos en los centros escolares, que posibilite la retención de docentes responsables de esta tarea y no solo por los logros académicos de sus estudiantes

- Considerar al alumnado como un actor clave, y facilitar espacios para que intervenga por sí mismo en los conflictos y reconozca, así, que es perfectamente capaz, a cualquier edad, de abordar sus propios conflictos

- Favorecer estrategias de intervención que se dirijan al mayor número posible de actores: no solo a un grupo seleccionado de mediadores entre iguales, sino a todo el alumnado; no solo a algunos miembros del cuerpo docente, sino a todo el personal del centro escolar

- Crear oportunidades para involucrar a toda la comunidad en el proceso de educación para la transformación de conflictos a fin de construir puentes entre la escuela y la comunidad

- Garantizar la formación suficiente del profesorado mediante cursos de formación inicial y continuada del profesorado en transformación de conflictos y convivencia: instaurando una asignatura obligatoria en todas las universidades que ofrecen grados y maestrías de educación (educación infantil, magisterio, pedagogía, máster de profesorado de secundaria y formación profesional en carreras relacionadas con la educación); ofreciendo cursos de formación continuada, preferiblemente dirigida a todo el personal de un mismo centro educativo, para fomentar que se introduzca la transformación de conflictos de forma estructural en el centro escolar; y difundiendo de manera pública la información sobre estos cursos (demanda, programas, número de cursos, duración) para posibilitar la evaluación de las políticas de formación inicial y continuada de transformación de conflictos
\end{abstract}

Fuente: Basado en Delvou et al., 2018.

\title{
CONCLUSIONES
}

El análisis comparativo de políticas ha permitido identificar algunas buenas prácticas de formación docente en los países estudiados. En primer lugar, destaca el hecho de que, en Suecia, el profesorado debe instruirse en gestión de conflictos desde la formación universitaria. Esta inclusión en los estudios iniciales, como en 
la University of Umeå, no solo permite capacitar al mayor número de docentes, sino que institucionaliza el contenido de transformación de conflictos como un contenido esencial del saber docente y de las futuras competencias del alumnado para aprender a vivir juntos.

En segundo lugar, la regulación de que la oferta de cursos de formación continuada deba incluir, necesariamente, contenidos de transformación de conflictos, como sucede en Francia, también reconoce su carácter esencial de la práctica docente, aunque no se considere esencial para su preparación inicial.

Por último, destaca la recolección de datos sobre conflictos en los centros por parte del profesorado (Suecia, Italia), cuando esta se convierte en una forma de práctica reflexiva y, por tanto, de aprendizaje, o la evaluación externa de programas implementados en las escuelas a largo plazo para obtener aprendizajes de la práctica (Croacia, Suecia).

De la reflexión acerca de las prácticas de estos países en formación docente en convivencia y transformación de conflictos, se concluyen cuatro observaciones: tal formación docente es imprescindible, pero insuficiente, incoherente e instrumental y, por ello, merece ser reforzada, reestructurada y reconceptualizada.

Imprescindible. De las tasas de incidencias de acoso escolar (10-11\% de alumnado victimizado por acoso y $14 \%$ por ciberacoso en los últimos dos meses) y de violencia física en las aulas (11\% de alumnado que participa en peleas en doce meses), a las que se podría añadir otras formas de violencia cultural y estructural, se desprende que es imprescindible tomar medidas al respecto. Si bien es poco probable que la formación docente resuelva todo el problema por sí sola, también es imprescindible que las personas que están más cerca de estos actos, y en especial el profesorado, esté capacitado para intervenir.

Insuficiente. La formación docente en transformación de conflictos que se imparte no se aplica de forma sistemática ni siquiera en aquellos países en que, como en Suecia y en Francia, está regulada por ley en la formación inicial o continuada. Para garantizar que esta formación de profesorado sea efectiva, además, sería necesario garantizar otras medidas, también actualmente insuficientes: destinar mayores recursos para la formación continuada del profesorado, recoger y analizar mejor información, cualitativa y cuantitativa, sobre cómo y cuánto aplica el profesorado estos aprendizajes en el aula y hasta qué punto mejora eso la convivencia y las competencias del alumnado para aprender a vivir en el aula y el mundo. Esto permitiría revisar las políticas de convivencia con base en necesidades -y evidencias- reales de aula.

Incoherente. Ligado a la reflexión anterior, hemos identificado una incoherencia considerable en los enfoques de las políticas educativas de formación de profesorado. Estas son cortoplacistas y no se mantienen en el tiempo, alternan diferentes enfoques (turnan aproximaciones positivas y negativas al conflicto y varían por completo el planteamiento en función de la alternancia partidista de los gobiernos), no dan seguimiento real del impacto y carecen de medios. También, hemos observado una incoherencia entre lo que está regulado por ley y la realidad, y hemos reconocido situaciones que ni siquiera la regulación legal garantiza que se ofrezca como contenido (España, Suecia, Francia); en cambio, hemos constatado la existencia de muy buenas prácticas al margen de las regulaciones de las políticas educativas. 
Instrumental. Se sigue priorizando la formación de profesorado como una manera para que la docencia pueda darse en condiciones de baja disrupción, por encima de un abordaje positivo del conflicto, cuando este surja entre actores de la comunidad educativa. Sin embargo, no se está promoviendo lo suficiente el enfoque de aprender a vivir juntos. Se reserva el aprendizaje del conflicto a espacios informales y puntuales cuando nacen estos (conflicto espontáneo como oportunidad educativa), pero no se planifican los espacios educativos para que se convierta en un aprendizaje consolidado por parte del alumnado.

Además de impulsar medidas para reducir las incidencias en las escuelas y promover un clima de mejor convivencia en ellas, es imprescindible formar en contenidos relacionados con el conflicto, la diversidad y la democracia. La importancia de incorporarlos en el currículo ya ha sido sostenida por Delors (1996) o Morin (1999) en documentos clásicos del mundo educativo desde hace más de dos décadas, pero siguen pendientes de ser integrados al currículo. Es necesario que el aprender a vivir juntos sea considerado un contenido curricular y desplegado como tal por etapas y áreas educativas. Tanto el argumento práctico -reducir el acoso y la violencia escolar y mejorar el clima de convivencia- como el formativo requieren una capacitación del profesorado específica en contenidos, habilidades y actitudes de transformación de conflictos.

Por ello, y para dar respuesta a las cuatro características apuntadas sobre la formación docente, este artículo se permite resumir las recomendaciones con apuntes en tres direcciones: refuerzo, reestructuración y reconceptualización. Sería conveniente reforzar la oferta de formación docente en transformación de conflictos, preferentemente desde la formación inicial, pero complementada, a la vez, con una formación continuada que garantice la aplicación de los aprendizajes en el aula (a través de la investigaciónacción, la práctica reflexiva, el acompañamiento en el aula, observación por pares) desde una diversidad metodológica. A la vez, es necesario reestructurar las políticas educativas para hacerlas más coherentes y asumibles: con objetivos realizables y evaluables de los cuales se pueda sacar lecciones para futuras reformulaciones de políticas educativas.

Finalmente, y en referencia a la reconceptualización, cabe seguir repensando el objetivo de la convivencia escolar, en la actualidad muy centrado en el clima escolar, pero no tanto en su potencial formativo (Fierro-Evans y Carbajal-Padilla, 2019). El valioso corpus conceptual existente en las intersecciones de la educación para la paz, la educación democrática y de derechos humanos, y la educación intercultural todavía no ha sido incorporado de manera suficiente en los currículos, y sería importante reconocerlo como un contenido relevante de la educación actual.

\section{REFERENCIAS BIBLIOGRÁFICAS}

Barbeito, C., Delvou, M., Ćosić, I., Fernandes, J., Hakwoort, I., Hennebo, M., Kostiainen, A., Kruhonja, K., Passerini, E. \& Renoux, C. (2018). Advocacy for nonviolent conflict transformation education: State of the art in five European cou$n$ tries and at the European level. Educate Project.

Burton, J. W. (1966). Conflict as a function of change. En A. de Reuck \& J. Kinght (eds.). Conflict and society (pp. 370-401). A Ciba Foundation Volume. Londres: Churchill. 
Cascón, P. (2001). Educar en y para el conflicto. Barcelona, España: Escola de Cultura de Pau-Universidad de Barcelona.

Comisión Europea (2018). Commission staff working document accompanying the document: Proposal for a council recommendation on key competences for lifelong learning. Brussels. https://ec.europa.eu/education/ sites/education/files/swd-recommendation-key-competences-lifelonglearning.pdf

Consejo de Europa (2016a). Competences for democratic culture. Living together as equals in culturally diverse democratic societies. Strasbourg: Council of Europe.

Consejo de Europa (2016b). Action plan on building inclusive societies. CM documents. http://www.theewc. org/Content/Library/COE-Steering-documents/Recommendations/Action-Plan-on-Building-Inclusive- Societies-2016-2019

Cremin, H. \& Bevington, T. (2017). Positive peace in schools. Tackling conflict and creating a cultura of peace in the classroom. Nueva York, NY: Routledge. https://doi.org/10.4324/9781315304236

Delors, J. (1996). Los cuatro pilares de la educación. En La educación encierra un tesoro. Informe a la Unesco de la Comisión Internacional sobre la Educación para el Siglo XXI (pp. 91-103). Madrid, España: Santillana/Unesco.

Delvou, M., Barbeito, C., Hakwoort, I., Kostiainen, A., Kruhonja, K., Passerini, E. \& Renoux, C. (2018). Documento de posición EduCATe ¡El profesorado es clave! Educate Project.

Díaz-Aguado, M. J., Martínez Arias, R. y Martín Babarro, J. (2010). Estudio estatal sobre la convivencia escolar en la educación secundaria obligatoria. Ministerio de Educación. https://sede.educacion.gob.es/ publiventa/estudio-estatalsobre-la-convivencia-escolar-en-la-educacion-secundaria-obligatoria/educacionsecundaria- socializacion/13567

Eurydice (2021). National Education Systems. Bruselas: Comisión Europea.

Fierro-Evans, C. y Carbajal-Padilla, P. (2019). Convivencia escolar: una revisión del concepto. Psicoperspectivas, vol. 18, núm. 1, pp. 1-14. http://dx.doi. org/10.5027/psicoperspectivas-vol18-issue1-fulltext-1486

Fisher, R. y Ury, W. (1991). Obtenga el sí. El arte de negociar sin ceder. CECSA.

Galtung, J. (2003). Paz por medios pacíficos. Paz y conflicto, desarrollo y civilización. Gernika: Bakeaz-Gernika Gogoratuz.

Galtung, J. (1990). Cultural violence. Journal of Peace Research, vol. 7, núm. 3.

Global Initiative to End All Corporal Punishment of Children (2020). Global report 2019: Progress towards ending corporal punishment of children. Londres: GIEACPC. http://endcorporalpunishment.org/wp-content/uploads/global/ Global-report-2019.pdf

Hakwoort, I., Kostiainen, A., Passerini, E., Barbeito, C., Ćosić, I., Delvou, M., Hennebo, M. \& Renoux, C. (2018). Teacher \& conflict: Where are we? State of the Art Report on Teacher training on non violent conflict transformation in Europe. Educate Project.

Inchley, J. et al. (eds.) (2020a). Spotlight on adolescent health and well-being. Findings from the 2017/2018 Health Behaviour in School-aged Children (HBSC) survey in Europe and Canada. International report (vol. 1). Key findings. Copenhagen: WHO Regional Office for Europe. 
Inchley, J. et al. (eds.) (2020b). Spotlight on adolescent health and well-being. Findings from the 2017/2018 Health Behaviour in School-aged Children (HBSC) survey in Europe and Canada. International report (vol. 2). Key data. Copenhagen: WHO Regional Office for Europe.

Johnson, D. W. \& Johnson, R. T. (1996). Conflict resolution and peer mediation pograms in elementary and secondary schools. A review of the research. Review of Educational Research, vol. 66, núm. 4, pp. 459-506.

Johnson, D. W., Johnson, R. T., \& Holubec, E. J. (1994). El aprendizaje cooperativo en el aula (p. 66). Association For Supervision and Curriculum Development.

Lederach, J. P. (2003). The Little book of conflict transformation. Intercourse, PA: Good Books.

Massip, C., Barbeito, C., Egea, A. \& Flores, M. (2018). Competències per transformar el món. Cap a una educació crítica i per a la justícia global a l'escola. Graó.

Maternowska, M. C., Potts, A. \& Fry, D. (2016). The multi-country study on the drivers of violence affecting children: A cross-country snapshot of findings. Florencia, Italia: Unicef Office of Research. https://www.unicef-irc.org/ publications/pdf/MCSDVAC_revised12072017.pdf

MECD (2016). Plan Estratégico de Convivencia Escolar (2016-2020). Madrid. https://www.mecd.gob.es/ dam/jcr:e411c039-2274-4533-a30223bc196d4420/plan-estrategico-convivencia-escolar.pdf

Ministère de l'Éducation Nationale (2015). Decret Socle commun de connaissances, de compétences et de culture n²015-372 du 31-3-2015 - J.0. du 2-42015. http://www.education.gouv.fr/pid25535/bulletin_officiel.html?cid_ bo=87834\#socle_commun

Morin, E. (1999). Los siete saberes necesarios para la educación del futuro. Unesco.

Morin, E. (1995). Introducción al pensamiento complejo. Barcelona: Gedisa.

OCDE (2018). Preparing our youth for an inclusive and sustainable world. The OECD PISA global competence framework. París. http://www.oecd.org/pisa/ Handbook-PISA-2018-Global-Competence.pdf

OCDE (2013). Croatia. Country Profile. http://www.iom.int/jahia/ webdav/ shared/shared/mainsite/activities/countries/docs/country_profile_cambodia.pdf

OCDE (2005). Definition and selection of key competences. Executive summary. http://www.oecd.org/pisa/35070367.pdf

Pregrad, J. (2015). Stop violence among children -Program Handbook. Therapy. Zagreb: unicef. http://unicef.hr/wp-content/ uploads/2016/01/SVAC_handbook_web_100dpi1.pdf

Richardson, D. \& Fen Hiu, C. (2016). Ending the torment: Tackling bullying from the schoolyard to cyberspace. Nueva York: United Nations. https://www. unicef.org/media/66536/file/Ending-the-torment.pdf

Rosenberg, M. B. (2006). Comunicación noviolenta. Un lenguaje de vida. Aldea editores.

Rosenwald, F. (2020). Enquête nationale 2018 de climat scolaire et de victimation auprès des lycéens: le point de vue des élèves internes. París: Ministère de l'Éducation Nationale et de la Jeunesse. 
Sidrera, F., Rostan, C., Agell, S., Serrat, E., Perpiñà, G., Collell, J., Ortiz, R., Mora, I. y Amadó, A. (2019). Bullying i ciberbullying a l'educació primària a Catalunya. Barcelona: Fundació Barça. https://fundacio.fcbarcelona.cat/documents / 30157/0/Bullying $+\mathrm{i}+$ Ciberbullying $+\mathrm{a}+1 \% 2$ 7 Educacio + Primaria+a+Catalunya.pdf/4cf45134-4302-a915-aa0c$1244002934 a 3 ? t=1588083178701$

Thapa, E., Cohen, J., Guffey, S. \& Higgins-D’Alessandro, A. (2013). A review of school climate research. Review of Educational Research, vol. 83, núm. 3, pp. 357-385.

Unesco (2017). Consolidated report on the implementation of the 1974 recommendation concerning education for international understanding, cooperation and peace and education relating to human rights and fundamental freedoms. Online report (39 C/25). http://unesdoc.unesco.org/ images/0025/002597/259734e.pdf

Unicef (2018). Una lección diaria. Acabar con la violencia en las escuelas. \#ENDViolence. Nueva York. https://www.unicef.org/spanish/publications/files/ An_Everyday_Lesson-ENDviolence_in_Schools_Sp.pdf 